\title{
ESTADO SOCIAL E SOCIEDADE CIVIL: REPENSANDO O PROGRAMA BOLSA FAMÍLIA A LUZ DOS CONCEITOS DE POBREZA E IGUALDADE DE AMARTYA SEM
}

\author{
Alessandra Barichello Boskovic ${ }^{1}$
}

\section{Resumo}

Em seu estudo sobre a justiça social, Amartya Sen afasta o critério tradicional de identificação da pobreza baseado no baixo nível de renda - e adota a ideia de pobreza enquanto privação de capacidades básicas, tais como saúde, educação, liberdade e oportunidade de emprego. Neste sentido, Sen constrói seu conceito de igualdade com base nesta mesma métrica: a igualdade de capacidades. Nesta perspectiva, a atuação isolada dos entes públicos pode não se mostrar suficiente, ganhando peso a proposta de Anthony Giddens para uma "terceira via", caracterizada pela sinergia entre os setores público e privado. Entretanto, o maior desafio à ativa participação da sociedade em ações assistenciais de cunho redistributivo pode estar em uma crise da solidariedade, inerente à hodierna sociedade individualista, e que decorre, nas palavras de Gilles Lipovetsky, de uma "sedução da desigualdade". No âmbito do Programa Bolsa Família, observa-se que a pobreza é combatida para além dos limites da renda, já que a proteção estabelecida estende-se também a importantes capacidades, como saúde e educação básica. Todavia, embora muitos de seus aspectos coadunem-se aos conceitos trazidos à análise neste estudo, resta um vasto campo a ser desenvolvido em relação a outras capacidades e ao fomento da bastante tímida participação civil.

Palavras-Chave: Pobreza; igualdade; Estado Social; terceira via; Programa Bolsa Família.

\section{INTRODUÇÃO}

O presente estudo tem por finalidade reexaminar o Programa Bolsa Família a partir dos conceitos de pobreza e igualdade formulados por Amartya Sen, observadas as responsabilidades do Estado (Social) e da sociedade civil.

Para tanto, encontra-se dividido em três seções principais. A primeira delas demonstrará que os conceitos tradicionais de pobreza e igualdade, pautados apenas no nível de renda, encontram-se superados. Neste sentido, serão apresentados os ideais de pobreza e de igualdade de capacidades sustentados por Amartya Sen.

A segunda seção versará sobre a insuficiência da atuação estatal na promoção da igualdade em termos de capacidades e sustentará, a partir da terceira via proposta por Anthony Giddens, a necessidade da participação da

\footnotetext{
${ }^{1}$ Doutoranda em Direito Econômico e Desenvolvimento pela Pontifícia Universidade Católica do Paraná. Professora do curso de Direito da Universidade Positivo e coordenadora do curso de Pós Graduação lato sensu em Direito e Processo do Trabalho na mesma instituição. E-mail: alessandra.boskovic@gmail.com
} 
sociedade civil. Enquanto maior desafio a esta sinergia entre o público e o privado, analisar-se-á a crise da solidariedade.

A quarta seção, por fim, examinará o Programa Bolsa Família à luz dos elementos discutidos nas seções anteriores, assinalando os pontos de identificação entre o programa e tais conceitos, apontando lacunas a serem desenvolvidas e sugerindo complementações.

\section{OS CONCEITOS DE POBREZA E IGUALDADE SEGUNDO AMARTYA SEN}

Em seu estudo sobre a justiça social, Amartya Sen afasta o critério tradicional de identificação da pobreza, qual seja, o baixo nível de renda. Em seu lugar, Sen adota a ideia de pobreza enquanto privação de capacidades básicas, entendidas estas como as "liberdades substantivas para levar o tipo de vida que se deseja levar" (SEN, 2000a, p. 109).

São três os argumentos apresentados para justificar a abordagem da pobreza como privação de capacidades. O primeiro defende que, neste enfoque, a ênfase é dada a privações que possuem importância intrínseca e, diferentemente do nível de renda, não apenas instrumental. É evidente que um elevado nível de renda tende a proporcionar amplas capacidades - e vice-versa - mas não há uma vinculação direta.

O segundo argumento consiste no fato de que a renda não é o único instrumento de geração de capacidades: baixos rendimentos são apenas um dentre os inúmeros elementos que influenciam na privação de capacidades - e, portanto, na pobreza real. A segurança pública, por exemplo, independe do fator renda e afeta diretamente as capacidades individuais.

Por fim, o terceiro argumento repousa na percepção de que a relação instrumental entre baixa renda e baixa capacidade é variável entre indivíduos, famílias ou comunidades. Este último argumento merece algumas considerações mais profundas.

A relação entre renda e capacidade pode ser afetada por diversos fatores, tais como idade (pessoas idosas ou muito jovens possuem necessidades específicas), papeis sociais (obrigações familiares, por exemplo), localização geográfica (riscos de inundações, secas, violência), dentre outras condições sobre as quais não se tem controle - ao menos não de forma absoluta. Sen sintetiza:

A extensão da desigualdade real de oportunidades com que as pessoas se defrontam não pode ser prontamente deduzida da magnitude da desigualdade de rendas, pois o que podemos ou não fazer, podemos ou não realizar, não depende somente das nossas rendas, mas também da variedade de características físicas e sociais que afetam nossas vidas e fazem de nós o que somos. (SEN, 2001, p. 60)

Em alguns casos, uma adversidade na conversão de renda em capacidades pode estar sobreposta aos baixos rendimentos. Certas desvantagens, como idade avançada ou enfermidades, restringem o potencial de um indivíduo para auferir renda, mas, além disso, tornam mais difícil a sua conversão em capacidades. 
Isso ocorre porque, exemplificativamente, uma pessoa idosa ou enferma pode demandar maior renda para obter as mesmas capacidades de uma pessoa jovem ou sadia - se é que isto, de algum modo, é possível - em razão de altos custos para tratamento médico, necessidade de acompanhamento constante, sofrimento imposto pela sua condição ou quaisquer outros motivos. Nesse sentido, a pobreza real (relativa à privação de capacidades) pode ser muito mais intensa e significativa do que a questão da renda poderia evidenciar. Este pode - e deve, segundo acreditamos - ser um elemento crucial na avaliação de políticas públicas de assistência a idosos ou outros grupos com limitada conversão de renda em capacidades em sobreposição à renda reduzida. (SEN, 2000a, p. 110111)

Esta nova perspectiva da pobreza proposta por Sen é inescapavelmente multidimensional, uma vez que existem distintas capacidades a serem valoradas. Há boas razões para valorizar, por exemplo, a não exclusão nas relações sociais - Flávia Piovesan reconhece, inclusive, o direito à inclusão social como um direito humano inalienável (PIOVESAN, 2003, p. 146-147). Neste sentido, a exclusão social pode ser considerada uma parte da pobreza de capacidades (SEN, 2000b, p. 4-5).

Ademais, ser excluído das relações sociais pode levar a outras privações, o que limita ainda mais as oportunidades de vida. Exemplifica-se: ser excluído da oportunidade de ter um emprego, ou de ter crédito, pode levar ao empobrecimento econômico - e este, por sua vez, pode conduzir a outras privações, tais como a falta de moradia ou desnutrição.

Há que se refletir com maior profundidade a distinção entre as duas formas pelas quais a exclusão social pode levar à privação de capacidades (SEN, 2000b, p. 13). Ser excluído pode ser, por si só, uma privação, e isso pode ser de importância intrínseca. Não ser capaz de participar da vida em comunidade, por exemplo, pode empobrecer diretamente a vida de uma pessoa. É uma perda em si própria, para além de tudo o mais que a privação possa ainda gerar indiretamente. Este é um caso de relevância constitutiva da exclusão social.

Em contraste, existem privações relacionais que não são em si mesmas ruins, mas que podem provocar resultados terríveis. Não ter acesso ao mercado de crédito, por exemplo, pode, por meio de relações causais, levar a outras privações, como a pobreza de renda ou a incapacidade de aproveitar eventuais oportunidades que poderiam ter sido gratificantes ou enriquecedoras, mas que teriam exigido um investimento inicial e uso de crédito.

Exclusões causais significativas desta ordem podem ter grande importância instrumental: as pessoas podem não estar empobrecendo em si, mas pode haver um empobrecimento da vida humana através das suas consequências causais (como a negação de oportunidades sociais e econômicas que seriam úteis para as pessoas envolvidas). Nesse sentido, o combate à pobreza de capacidades permeia o enfrentamento da exclusão social.

$\mathrm{Na}$ luta contra a pobreza de capacidades, há que se estabelecer que tipo de igualdade se almeja, já que 
esta, enquanto ideia abstrata, não possui muito poder de corte. A questão central, então, consiste na especificação do âmbito em que a igualdade deve ser encalçada e das "regras contábeis equitativas" que podem balizar a distribuição. Cada uma das teorias da justiça social volta-se a responder as indagações "igualdade de quê?" e "equidade em que forma?" (SEN; KLIKSBERG, 2010, p. 75).

As vantagens e desvantagens que uma pessoa pode possuir podem ser comparadas umas as outras - e julgadas - com base em inúmeras variáveis. Com isso, encontram-se diferentes critérios de definição do que é igualdade: de renda, de direitos, de utilidades, de liberdade, dentre muitas outras possibilidades (SEN, 2001, p. 51). Amartya Sen sugere a adoção da métrica utilizada na definição da pobreza para servir de indicador no processo de avaliação dos níveis da igualdade: as capacidades (SEN, 2011, p. 325).

O contraste entre diferentes perspectivas da renda e da capacidade influencia diretamente a análise da igualdade: uma pessoa excluída da participação política, mas com renda elevada, em que pese não seja pobre na acepção usual do termo, é claramente pobre no que tange a uma importante liberdade; uma pessoa que tenha renda maior do que a maioria, mas que sofra de uma doença cujo tratamento seja altamente custoso, suporta uma relevante privação; uma pessoa a quem seja negada a oportunidade de emprego mas que receba assistência do Estado (a exemplo do Programa Bolsa Família, que será tratado mais adiante) sofrerá menos privação no que tange à renda do que em função da valorizada oportunidade de ter uma ocupação gratificante (SEN, 2000a, p. 117).

Em que pese a perda de renda acarretada pelo desemprego possa ser compensada economicamente, em grande medida, pela assistência do Estado, a redução de capacidades provocada por ele não se equilibrada com a ajuda estatal. Sen argumenta que os efeitos do desemprego vão além da redução da renda e incluem danos psicológicos, perda de motivação para o trabalho, perda de habilidade e autoconfiança, aumento de doenças, perturbações nas relações familiares e sociais e muitas outras consequências. Neste sentido, a melhora promovida pelo 'auxílio-renda' é limitada (SEN, 2000a, p. 117).

Numa abordagem que trate a pobreza e a igualdade como valores relacionados não apenas à renda, mas sim às capacidades, a atuação isolada dos entes públicos pode não se mostrar suficiente. Na próxima seção demonstrar-se-á a importância da participação civil na persecução destes ideais e os desafios que a solidariedade enfrenta na sociedade hodierna.

\section{O ESTADO SOCIAL E A TERCEIRA VIA}

A relação existente entre o Estado e os direitos sociais se modificou muito ao longo do último século. Já na segunda década do século XX, no rastro da primeira guerra mundial, as Constituições Mexicana e de Weimar renegaram o modelo liberal de Estado mínimo e atribuíram-lhe responsabilidades sociais. 
Nos Estados Sociais o poder público exerce um papel central na proteção e promoção de direitos sociais, tais como educação, saúde, alimentação, trabalho, segurança e assistência aos desamparados. O combate à pobreza e a persecução da igualdade também fazem parte da welfare agenda (JAKOBI, 2010, p. 205-209).

A proteção social oferecida pelo Estado, contudo, mostra-se insuficiente. Isso acontece porque as políticas adotadas pelos sistemas de welfare frequentemente se apresentam aquém do ótimo desejado - as necessidades humanas são ilimitadas, ao passo que o orçamento público é limitado - ou estabelecem situações de perigo moral.

O perigo moral se caracteriza, de acordo com Anthony Giddens, quando pessoas se valem da proteção social existente para modificar o comportamento que naturalmente teriam caso aquela proteção não existisse. É o que certas vezes acontece com benefícios que oferecem proteção ao desemprego: caso sejam utilizados ativamente como proteção contra o mercado de trabalho, podem acabar por majorar o desemprego que visavam combater (GIDDENS, 1999, p. 124-125).

Giddens ressalta que quanto maior o espaço de tempo em que os benefícios sociais sejam concedidos, maior o risco do perigo moral. Isso ocorre "porque a longo prazo formam-se hábitos sociais que passam a definir o que é 'normal'. "Nesse cenário, uma generalizada dependência dos benefícios não mais é compreendida como tal e passa a ser um comportamento "esperado" (GIDDENS, 1999, p. 125).

Assim, Giddens sustenta o que ele denomina de welfare positivo. Considerando que o welfare não é um conceito essencialmente econômico, mas sim psicológico, na medida em que concerne ao bem-estar, benefícios puramente econômicos se mostram insuficientes. Por isso, sempre que possível, investimentos devem ser concentrados em capital humano, e não no provimento direto de sustento econômico. Para tanto, os membros da sociedade civil devem retomar sua responsabilidade pessoal (GIDDENS, 1999, p. 127).

Christophe Dejours argumenta que crer que o desemprego e a exclusão social decorrem de uma injustiça, ou, ao contrário, acreditar que resultam de uma crise pela qual ninguém é responsável "não é algo que dependa de uma percepção, de um sentimento, ou de uma intuição, como o é no caso do sofrimento". A questão da justiça ou da injustiça envolve primeirissimamente a questão da responsabilidade pessoal, ou seja, deve-se indagar se a responsabilidade de determinados governantes e a reponsabilidade pessoal de cada membro da sociedade estão ou não implicadas nessas adversidades (DEJOURS, 1999, p. 20).

Neste sentido, Giddens sugere uma nova economia mista, em superação à antiga. Lembre-se que na velha economia mista existiram dois modelos: um que envolvia a separação entre o Estado e os setores privados, mas no qual grande parte da indústria concentrava-se em mãos públicas; e outro que era - e é - o mercado social. Em ambos os casos, contudo, os mercados subordinam-se amplamente ao governo (GIDDENS, 1999, p. 109).

A nova economia mista - que Giddens denomina "a terceira via" - busca uma sinergia entre os setores 
público e privado, valendo-se do dinamismo de mercado, mas com vistas ao interesse público. Isso envolve um equilíbrio entre regulação e desregulação, bem como entre o econômico e o não econômico na vida em sociedade.

Neste sentido, a igualdade precisa ser repensada de forma cuidadosa, posto que "deve contribuir para a diversidade, ao contrário de bloquear seu caminho". Giddens não pretende, com isso, suprimir do programa da social-democracia a redistribuição, mas, ao invés disso, busca redirecionar a ideia da redistribuição de riqueza para a redistribuição de possibilidades. "O cultivo do potencial humano deveria na medida do possível substituir a redistribuição a posteriori" (GIDDENS, 1999, p. 110-111).

Para tanto, a retomada do espaço público (que ele denomina "liberalismo cívico") deve ser tida como premissa de uma sociedade inclusiva. Indivíduos que se sentem membros de uma comunidade nacional costumam reconhecer que possuem um compromisso com os demais membros desta comunidade (GIDDENS, 1999, p. 116-117).

Considerando que a exclusão tende a ser auto-reprodutiva, evidentemente quaisquer iniciativas que rompam ciclos de pobreza devem ser incentivadas. Todavia, Giddens defende que os programas convencionais de socorro à pobreza sejam substituídos por ações voltadas à comunidade. Isso porque o desenvolvimento de comunidades reforça as redes de apoio e o ímpeto empreendedor, cultivando o capital social como mecanismo de renovação econômica em localidades de baixa renda (GIDDENS, 1999, p. 119-120).

Deixar as pessoas se atolarem em beneficios tende a excluí-las da sociedade mais ampla. Reduzir os benefícios para forçar indivíduos a trabalhar empurra-os para mercados de trabalho de baixos salários, já abarrotados. As iniciativas de formação de comunidade concentram-se nos múltiplos problemas que os indivíduos e as famílias enfrentam, entre os quais a qualidade do emprego, a assistência à saúde e à infância, a educação e o transporte. (GIDDENS, 1999, p. 120)

Uma grande dificuldade encontrada quanto à participação privada na proteção social é a crescente individualidade presente naquela que Gilles Lipovetsky denomina de "sociedade pós-moralista”. Segundo o autor, o hodierno individualismo não decorre de um maior egoísmo do homem contemporâneo, mas de uma maior aceitação social do caráter individualista de suas preferências: "a novidade está precisamente nisto: pensar só em si não é mais tido como algo imoral" (LIPOVETSKY, 2005, p. 107).

Enquanto aos olhos do ideal moral o indivíduo não goza de direitos, pois the compete tão somente o exercício de deveres, a cultura pós-moralista supervaloriza a legitimidade dos direitos subjetivos e solapa o espírito do sacrifício, o ideal de dar precedência aos outros. "A nova era individualista conseguiu a façanha de atrofiar nas consciências a alta consideração de que desfrutava o ideal altruísta, redimiu o egocentrismo e legitimou o direito de viver só para si” (LIPOVETSKY, 2005, p. 107).

Se, contudo, Lipovetsky acredita ser o altruísmo um valor desacreditado, o mesmo não se passa com a "solidariedade-caridade". Grandes eventos midiáticos com finalidade caritativa, por exemplo, arrecadam elevados 
valores pecuniários todos os anos ${ }^{2}$. Não é, portanto, o princípio do auxílio caritativo que perdeu sua justificação, e sim o ideal de ajudar ao próximo mesmo quando isto cause a si próprio um desconforto.

Ironiza Lipovetsky: "generosidade, vá lá, contanto que seja algo fácil e distante, sem ligação com esta ou aquela forma superior de renúncia. Somos tendentes à solidariedade, desde que não nos envolva por completo" (LIPOVETSKY, 2005, p. 109).

Neste sentido, muitas pessoas se predispõem a efetuar uma ligação telefônica ou um acesso à internet do conforto de seus lares para doarem pequenas quantias em dinheiro à caridade enquanto assistem a dinâmicos programas de televisão que os incentivam a tanto. Todavia, uma parcela bastante reduzida deste público teria a iniciativa de promover uma ação caritativa ou estaria disponível para doar seu tempo e energia para implementálo.

O que explica esta diferença é o fato de que o individualismo hodierno não extingue a preocupação ética, mas origina um "altruísmo indolor de massa": dilui-se o ideal de renúncia sistemática e admite-se apenas a dedicação pontual, especialmente em contextos emergenciais, tais como situações excepcionais de vida e de morte. É o que Lipovetsky denomina de "ética minimalista e intermitente" (LIPOVETSKY, 2005, p. 109).

Este espírito solidário-caritativo minimalista e intermitente torna-se mais presente quando há algum tipo de identificação entre o indivíduo que se doa e a pessoa ou grupo que recebe a caridade. Richard Rorty defende que o sentimento de solidariedade encontra sua intensidade máxima quando aqueles com quem nos solidarizamos são reconhecidos como "um de nós" (RORTY, 2007, p. 314-315).

A expressão "um de nós" é adotada por Rorty para representar algo mais específico do que a raça humana. De acordo com esta visão, as pessoas solidarizam-se umas em relação às outras não pelo simples fato de serem todas seres humanos, mas pela presença de outro elemento qualquer que subjetivamente dê-lhes o sentimento de proximidade e pertencimento. Assim, solidarizamo-nos com outra pessoa por ser ela nossa conterrânea ou colega de profissão, por pertencermos à mesma faixa etária ou ao mesmo grupo social ou étnico, por termos características em comum que nos incutam o sentimento de empatia.

Diante de um terrível desastre natural, por exemplo, que foge muitas vezes ao controle humano, a empatia e a solidariedade surgem naturalmente, na medida em que se trata de uma situação emergencial extrema, que envolve vida e morte, mas que, principalmente, poderia ocorrer com qualquer pessoa que estivesse naquele momento naquele local. Todavia, quando o debate retorna ao campo da redistribuição de renda - ou de capacidades - a questão ganha complexidade.

\footnotetext{
${ }^{2}$ Com a finalidade de ilustrar tal afirmação, apresentam-se os resultados dos dois principais eventos televisivos com finalidade caritativa realizados no Brasil: o programa Criança Esperança e o Teleton. No ano de 2013 estes eventos arrecadaram mais de R\$ 10 milhões e R \$ 26 milhões em doações, respectivamente. Em 2014, o Criança Esperança totalizou mais de R \$15 milhões em doações e o Teleton arrecadou mais de R\$30 milhões (PORTAL G1, 2013); (PORTAL G1, 2014); (JOVEM PAN, 2013); (SBT, 2014).
} 
As sociedades ocidentais contemporâneas, em maior ou menor escala, valorizam o sucesso individual pautado no mérito. Este signo decorre de uma "alquimia social" na qual se fundem aptidão, motivação, desejo, coragem e habilidade sob o signo "mérito" (SENNET, 2004, p. 118).

Em uma sociedade ou comunidade meritocrata valorizam-se as "carreiras abertas ao talento", o que significa que o sujeito talentoso (esforçado e corajoso) tem o direito de mostrar o que pode fazer por si e de ser valorizado por isso. Quanto mais destaque e reconhecimento o indivíduo angariar, então mais mérito ele possui. Há, no entendimento de Richard Sennet, uma "sedução da desigualdade": a aristocracia artificial, pautada na riqueza ou na posição social, cede espaço a uma aristocracia natural, fundada no talento (SENNET, 2004, p. 111 115).

Nesse sentido, a parcela da população com mais confortáveis condições de engajamento solidário na caridade redistributiva encontra dois obstáculos principais. O primeiro deles é a reduzida identificação com o grupo a ser favorecido pela medida (o que, como visto, solapa o sentimento de empatia e, por consequência, de solidariedade).

O segundo desafio consiste no enfrentamento da sedução da desigualdade inerente à meritocracia, que facilmente conduz à crença de que a pessoa ou grupo vulnerável encontra-se em tal condição por ausência de mérito, e que, portanto, vive uma realidade "merecida". Ademais, a sedução da desigualdade, contraposta às medidas redistributivas, pode provocar nos grupos mais abastados um sentimento de injustiça, na medida em que a redistribuição deixa de enaltecer as conquistas alcançadas pelos talentosos - e merecedores, segundo este raciocínio - para redistribuí-las a quem, em última análise, não as merece.

Deste modo, há uma tendência à inércia na sociedade civil no que tange à participação em políticas sociais de redistribuição de renda. Este é o maior desafio à necessária sinergia entre Estado e sociedade defendida por Giddens.

Na próxima seção, analisar-se-á o Programa Bolsa Família à luz dos papeis do Estado e da sociedade, tomando-se as capacidades enquanto métrica para aferição da pobreza e persecução da igualdade.

\section{POBREZA E IGUALDADE, ESTADO E SOCIEDADE: O PROGRAMA BOLSA FAMÍLIA}

O modelo de Estado Social se evidencia pela primeira vez no Brasil no texto constitucional de 1934, influenciado pelas já citadas Constituições Mexicana e de Weimar, mas é na Constituição Federal de 1988 que alcança seu apogeu (DISSENHA, 2010, p. 334-335).

Uma larga cartela de direitos sociais a serem garantidos e promovidos pelo Estado encontra-se consignada na lei maior, mas no presente estudo é o artigo 6 $6^{\circ}$, com redação dada pela Emenda Constitucional n. 64/2010, que merece maior destaque. São garantidos, dentre outros, os direitos sociais à saúde, à alimentação, ao 
trabalho, à moradia e, no que tange à distribuição de renda, o direito à assistência social.

Os objetivos das políticas assistenciais, de acordo com o texto constitucional, serão: a proteção à família, à maternidade, à infância, à adolescência e à velhice; o amparo às crianças e adolescentes carentes; a promoção da integração ao mercado de trabalho; a habilitação e reabilitação das pessoas com deficiência e a promoção de sua integração à vida comunitária; e a garantia de um salário mínimo de benefício mensal à pessoa com deficiência e ao idoso que comprovem não possuir meios de prover sua própria manutenção ou de tê-la provida por sua família (BRASIL, 1988, art. 203). Para dar efetividade à norma constitucional, a assistência social é promovida através de diversos programas e benefícios, dentre os quais o Programa Bolsa Família (PBF). ${ }^{3}$

O PBF foi criado no ano de 2003 por meio da Medida Provisória n. 132, convertida na Lei n. 10.836/2004, que unificou os procedimentos de gestão e execução das ações de transferência condicionada de renda do governo federal existentes até então (Programa Nacional de Renda Mínima vinculada à Educação; Programa Nacional de Acesso à Alimentação; Programa Nacional de Renda Mínima vinculada à Saúde; Programa Auxílio-Gás; Cadastramento Único do Governo Federal).

Este programa atende as famílias em situação de pobreza e extrema pobreza, assim caracterizadas segundo a renda familiar mensal per capita. ${ }^{4}$ Os valores estabelecidos para enquadramento, vigentes no ano de 2014, eram de até $\mathrm{R} \$ 154,00$ (cento e cinquenta e quatro reais), para a situação de pobreza, e de R \$77,00 (setenta e sete reais), para a extrema pobreza (BRASIL, 2004, art. 18).5

Os benefícios do PBF são de quatro naturezas: (i) benefício básico, pago às unidades familiares que se encontrem em situação de extrema pobreza; (ii) benefício variável, pago às unidades familiares que se encontrem em situação de pobreza e extrema pobreza e nas quais haja gestantes, nutrizes, crianças ou adolescentes com idade até quinze anos (pago até o limite de cinco benefícios por família); (iii) benefício variável, vinculado ao adolescente, pago às unidades familiares que se encontrem em situação de pobreza ou extrema pobreza e que tenham em sua composição adolescentes com idade entre dezesseis e dezessete anos (pago até o limite de dois benefícios por família); (iv) benefício para superação da extrema pobreza pago às famílias beneficiárias do PBF que tenham em sua composição crianças e adolescentes com até quinze anos de idade, e, ainda, que apresentem soma da renda familiar mensal e dos beneficios financeiros anteriores igual ou inferior a $\mathrm{R} \$ 70,00$ (setenta reais) per capita (pago apenas um por família) (BRASIL, 2004, art. 2º).

\footnotetext{
${ }^{3} \mathrm{O}$ benefício de prestação continuada (BPC), por exemplo, consiste na garantia de um salário-mínimo mensal à pessoa com deficiência e ao idoso com sessenta e cinco anos, ou mais, que comprovem não possuir meios de prover a própria manutenção nem de tê-la provida por sua família. Já os serviços socioassistenciais são atividades continuadas que com foco na melhoria de vida da população. Como estes, existem outras políticas assistenciais em vigor no Brasil. Em virtude do recorte temático estabelecido, este estudo limita-se à análise do Programa Bolsa Família. (BRASIL, 1998, arts. 20-23) (BRASIL, 1988, art. 203)

${ }^{4}$ Considera-se renda familiar mensal a soma dos rendimentos brutos auferidos mensalmente pela totalidade dos membros da família, excluindo-se os rendimentos concedidos por programas oficiais de transferência de renda (BRASIL, 2004a, art. $2^{\circ}, \$ 1^{\circ}$, III). ${ }^{5}$ Redação do artigo 18 dada pelo Decreto 8.232/14.
} 
Ao estabelecer uma proteção diferenciada às unidades familiares que possuam gestantes, nutrizes, crianças ou adolescentes em sua composição, o PBF coaduna-se ao entendimento de Amartya Sen. Isso porque em tais casos a conversão de renda em capacidades pode ser menos efetiva se comparada à das pessoas em geral. Nesta esteira, outros grupos de risco, tais como os idosos e as pessoas com deficiência, também deveriam ser objeto de assistência específica no âmbito do PBF.

Os objetivos básicos do programa, em relação aos seus beneficiários, são a promoção do acesso à rede de serviços públicos, especialmente à saúde, educação e assistência social; o combate à fome e a promoção da segurança alimentar e nutricional; o combate à pobreza; e a promoção da intersetorialidade, complementaridade e sinergia das ações sociais do Poder Público (BRASIL, 2004a, art. 4).

Neste sentido, observa-se, em apertada síntese, que o PBF concentra-se essencialmente no combate à pobreza em sua acepção tradicional (ou seja, de renda) e, de forma indireta, na proteção à saúde, à educação e à alimentação. Outras capacidades já mencionadas neste estudo, tais como a inclusão social (tomada minimamente como a ausência de exclusão) e a ampla oportunidade de emprego passam à margem deste programa assistencial.

A concessão dos benefícios do PBF dependerá do cumprimento de condicionalidades, naquilo que couber, sendo estas as principais: (i) quanto à saúde: exame pré-natal das gestantes, acompanhamento das nutrizes com idade entre quatorze e quarenta e quatro anos, e, quanto às crianças menores de sete anos, acompanhamento do calendário de vacinas, do crescimento e desenvolvimento; (ii) quanto à educação: matrícula e frequência escolar em estabelecimento de ensino regular para jovens com idade até dezessete anos (BRASIL, 2004b, art. 3).

A estruturação do PBF está, portanto, focada na distribuição de recursos financeiros, mas vinculada à prática de algumas condutas por parte do beneficiário. A exigência de atendimento a tais condicionalidades para a concessão do benefício não possui condão punitivo; sua natureza é protetiva, posto que visa ao desenvolvimento de capacidades tomadas pelo poder público como relevantes.

Na medida em que implementa condicionalidades vinculadas, por exemplo, à matrícula e frequência do jovem à escola, o Programa incentiva o desenvolvimento de capacidade importantíssima na persecução da igualdade de Amartya Sen. Mas isto não se mostra suficiente.

$\mathrm{Na}$ seção inicial deste estudo já se discutiu os impactos negativos que o desemprego produz para além da questão da renda. A assistência financeira do Estado ameniza a pobreza em termos financeiros, mas não em relação às capacidades em geral. Neste sentido, falta ao PBF a implementação de ações focadas na facilitação da inserção profissional dos beneficiários.

Ademais, ao adotar critérios para concessão de benefícios baseados apenas na renda e nos membros que integram a unidade familiar - em que pesem as condicionalidades - o PBF não apenas deixa de proteger a 
importante capacidade que é a oportunidade de emprego como, em determinados contextos, limita-a. Explica-se: em localidades extremamente pobres, onde vigora um mercado de trabalho de baixíssimos salários, as pessoas podem não se sentir motivadas a se submeterem a um emprego formal que lhes renderia muito pouco além dos valores recebidos da assistência social.

Todavia, se ao critério de renda acrescentasse-se o elemento "emprego formal", esta capacidade poderia ser melhor tutelada. Neste cenário, a renda per capita máxima apresentada pela família para fins de concessão do benefício deveria ser relativamente mais elevada para beneficiários que possuam relação de emprego anotada em carteira de trabalho (CTPS) ou que comprovem ter buscado uma colocação profissional, ainda que sem sucesso, em período de tempo a ser definido em regulamentação.

Se, de um lado, tais pessoas não seriam tão pobres (na acepção tradicional do termo) quanto aquelas que não possuem emprego formal, sob a ótica da igualdade de capacidades o resultado alcançado pelo PBF poderia ser potencializado.

Ademais, novas condicionalidades poderiam ser instituídas a fim de ampliarem-se as oportunidades de emprego. No quesito educação, por exemplo, seria adequada a inclusão de capacitação profissional às pessoas maiores de dezoito anos, ao menos para aquelas que se encontrem desempregadas há mais de um ano. ${ }^{6}$ Com esta nova condicionalidade estar-se-ia fomentando duas relevantes capacidades - educação e oportunidade de emprego - de uma só vez.

Uma outra capacidade citada na primeira seção deste estudo é a não exclusão. Dentre as formas de promove-la, conforme já discorrido, está a participação das pessoas no espaço público. Neste sentido, falta ao PBF o estabelecimento de condicionalidades ligadas às obrigações cívicas estabelecidas em lei, tais como, a título exemplificativo, alistamento militar e participação eleitoral. ${ }^{78}$

No que tange ao papel da sociedade, exaltado por Giddens, observa-se que o texto constitucional brasileiro reserva-lhe um papel ativo na promoção do bem estar social: "a seguridade social compreende um conjunto integrado de ações de iniciativa dos Poderes Públicos e da sociedade” (BRASIL, 1988, art. 194). No âmbito normativo-constitucional é possível afirmar, portanto, que encontra-se presente a sinergia entre poder público e sociedade civil sustentada pela terceira via.

Em plano infraconstitucional, contudo, a previsão normativa de participação privada na assistência social

\footnotetext{
${ }^{6}$ Para tanto bastaria a articulação do PBF com outros projetos já existentes, a exemplo do PRONATEC (Programa Nacional de Acesso ao Ensino Técnico e Emprego).

${ }^{7} \mathrm{O}$ alistamento militar é obrigatório nos termos do artigo 20 da Lei 4.375 de 17 de agosto de 1964 (Lei do Serviço Militar). O alistamento eleitoral e o voto são obrigatórios de acordo com o artigo 6º da Lei 4.737 de 15 de julho de 1965 (Código Eleitoral).

${ }^{8}$ A vinculação do benefício assistencial à participação política materializada por meio do voto pode suscitar questionamentos relacionados a um possível mal uso do PBF enquanto ferramenta para angariação de votos. Destaca-se que este é um estudo acadêmico que pretende refletir o Programa Bolsa Família sob a perspectiva da igualdade de capacidades unicamente no plano jurídico-filosófico. Os usos políticos - arbitrários ou não - que na prática possam ser feitos do PBF fogem ao escopo desta análise.
} vol. 08, no. 04, Número Especial. Rio de Janeiro, 2015.pp. 2304-2319 
(e especialmente no PBF) é bastante singela - e a realidade fática mostra-se ainda mais modesta.

Ilustra-se: o Decreto n. 5.209/04, que regulamenta o PBF, determina que o Ministério do Desenvolvimento Social e Combate à Fome (MDS), juntamente com instituições públicas e da sociedade civil, promova ações coordenadas e continuadas destinadas à inserção e educação financeiras dos beneficiários do programa (BRASIL, 2004a, art. 26-C). A ação mais significativa até o momento foi a elaboração de uma cartilha financeira pelo próprio MDS, cuja impressão recebeu apoio financeiro da Caixa Econômica Federal, uma empresa pública.

Esta realidade pode ser atribuída, ao menos em parte, à já aludida sedução da desigualdade inerente às sociedades com apelo meritocrata. Por esta razão, passa-se a enfrentar os dois principais obstáculos à participação mais ativa da sociedade no PBF, apresentados na seção anterior.

O primeiro deles, lembre-se, consiste na comum falta de identificação entre quem possui meios para agir e quem necessita assistência, o que acarreta uma "crise de solidariedade". Para contornar este entrave, é essencial que se trabalhe a dissolução dos estereótipos negativos relacionados aos beneficiários do PBF pois, a partir disso, aumenta-se a probabilidade de que tais famílias passem a ser vistas pelos demais membros da sociedade como "um de nós".

Neste sentido, o levantamento de dados empíricos confiáveis e a sua adequada divulgação podem apresentar resultados positivos. A título ilustrativo, apresentam-se a seguir duas interessantes informações.

É bem verdade que nos estados do norte e nordeste brasileiro a proporção de famílias que recebem benefícios do PBF em relação às demais é muito mais elevada do que nas demais regiões (CAMARGO et al, 2013, p. 163). Todavia, se considerada a densidade demográfica em todo o território nacional, é possível observar que em números absolutos a região sudeste é a que mais possui beneficiários do programa.

Segundo dados do Ministério do Desenvolvimento Social e Combate à Fome, dentre todas as famílias beneficiadas pelo PBF em dezembro de 2013, 33,45\% encontravam-se na região sudeste, 29,53\% na região nordeste, $17,75 \%$ na região norte, $9,93 \%$ na região sul e 9,32\% na região sudeste (MINISTÉRIO DO DESENVOLVIMENTO SOCIAL E COMBATE À FOME, 2013, p. 21).

Uma segunda informação relevante refere-se à taxa de fecundidade. Embora seja bastante comum a crença de que muitos beneficiários do PBF estariam gerando mais filhos com intuito de usufruir maiores benefícios assistenciais, um estudo realizado no ano de 2012 evidenciou que a taxa de fecundidade entre beneficiários do programa é muito semelhante à média nacional, mas abaixo desta (SIMÕES; SOARES, 2012).

Quanto ao segundo obstáculo, relativo ao sentimento de injustiça que a cultura meritocrata pode provocar em algumas pessoas diante de uma política redistributiva, pensa-se que uma possível resposta poderia ser construída com base na teoria da justiça de John Rawls. 
Caso um "véu da ignorância" recaísse sobre os indivíduos que integram uma comunidade, deixando-os em completo desconhecimento quanto aos seus talentos, aptidões, idade, condições de saúde, posição social e condição financeira pré-existentes, seriam eles favoráveis a uma política que garantisse assistência mínima àqueles em situação de miséria (tomada no sentido de Sen) ou vulnerabilidade no que tange à conversão de renda em capacidades? (RAWLS, 2000, p. 146-153) (CAMARGO et al, 2013, p. 163)

Arrisca-se afirmar que a decisão majoritária seria, muito provavelmente, no sentido de que tal proteção assistencial é justa. No que tange aos critérios para concessão de benefícios, por outro lado, diversas poderiam ser as posições sustentadas - mas esta é uma questão secundária, na medida em que o que se procura, neste momento da análise, é tão somente trazer a sociedade civil à participação ativa no PBF tal como deseja a terceira via e o texto constitucional brasileiro.

Deste modo, embora muitos aspectos do PBF coadunem-se aos conceitos trazidos à análise neste estudo, resta um vasto campo a ser desenvolvido de forma a fomentar a participação civil. Ademais, em que pese o programa esteja atento à pobreza para além dos limites da renda, muitas outras capacidades poderiam ser facilmente inseridas no seu âmbito de proteção.

\section{CONSIDERAÇÕES FINAIS}

Analisando-se o Programa Bolsa Família à luz de conceitos como a pobreza e a igualdade de capacidades de Amartya Sen, observa-se um amadurecimento das políticas assistenciais brasileiras no sentido de aliarem à distribuição de renda outras importantes capacidades, como saúde e educação. Todavia, ainda há muito o que ser aprimorado. A inclusão de novas condicionalidades, que promovam um número maior de capacidades, seria um importante passo neste processo.

No que tange à parceria entre o público e o privado sustentada por Anthony Giddens, observa-se uma incipiente participação da sociedade civil nos programas assistenciais, mas que carece maior fomento para o despertar de uma efetiva terceira via. A crise da solidariedade, decorrente, em boa medida, da sedução da desigualdade, parece ser o principal desafio. 


\title{
SOCIAL STATE AND CIVIL SOCIETY: RETHINKING THE PROGRAM "BOLSA FAMÍLIA" IN THE LIGHT OF THE CONCEPTS OF POVERTY AND EQUALITY BY AMARTYA SEN
}

\begin{abstract}
In his study of social justice, Amartya Sen refuses the traditional criterion of poverty identification, based only on low incomes. Instead, Sen adopts the idea of poverty as deprivation of basic capabilities such as health, education, freedom and employment opportunities. Thus, Sen builds his concept of equality based on this same metric: capabilities equality. In this perspective, the isolated actions of public bodies may not be enough. Therefore, in this context, the idea of Anthony Giddens for a "third way" seems appropriate. The "third way" is characterized by the synergy between the public and private sectors. However, the biggest challenge to the active participation of society in redistribution policies may be a crisis of solidarity present in the current individualist society, that derives, in the words of Gilles Lipovetsky, from a "seduction of inequality". In "Programa Bolsa Família" (Brazilian Family Grant Program) it is observed that poverty is battled not only in terms of income, as the established protection also extends to important capabilities such as health and basic education. However, while many of its aspects are similar to the concepts brought to analysis in this study, there remains a vast field to be developed in relation to other capabilities and in fostering civic participation.
\end{abstract}

Keywords: Poverty; equality; Welfare state; third way; Programa Bolsa Família (Brazilian Family Grant Program)

\section{REFERÊNCIAS}

BRASIL. Constituição da República Federativa do Brasil, 1988.

Decreto 5.209, de 17 de setembro de 2004. Regulamenta a Lei no 10.836, de 9 de janeiro de 2004, que cria o Programa Bolsa Família, e dá outras providências. Diário Oficial da União, Brasília, DF, 20 set. 2004a. 1964.

Lei 4.375, de 17 de agosto de 1964. Lei do Serviço Militar. Diário Oficial da União, Brasília, DF, 3 set.

Lei 4.737, de 15 de julho de 1965. Institui o Código Eleitoral. Diário Oficial da União, Brasília, DF, 19 jul. 1965 e retificado em 30 jul. 1965.

Lei 8.742, de 7 de dezembro de 1993. Dispõe sobre a organização da Assistência Social e dá outras providências. Diário Oficial da União, Brasília, DF, 8 dez. 1998.

Lei 10.836 de 9 de janeiro de 2004. Cria o Programa Bolsa Família e dá outras providências. Diário Oficial da União, Brasília, DF, 8 out. 2004b.

CAMARGO, Camila Fracaro; CURRALERO, Claudia Regina Baddini; LICIO, Cristina; MOSTAFA, Joana. Perfil socioeconômico dos beneficiários do programa bolsa família: o que o cadastro único revela? In: CAMPELLO, Tereza; NERI, Marcelo Côrtes (Org.). Programa Bolsa Família: uma década de inclusão e cidadania. Brasilia: IPEA, 2013.

DEJOURS, Christophe. A banalização da injustiça social. Tradução de Luiz Alberto Monjardim. 2. ed. Rio de Janeiro: Editora FGV, 1999. 
DISSENHA, Leila Andressa. As relações trabalhistas e a "pós-modernidade". In: VILLATORE, Marco Antônio César; HASSON, Roland. (Coord.). Estado \& atividade econômica: o direito laboral em perspectiva. Curitiba: Juruá, 2010.

GIDDENS, Anthony. A Terceira via. Tradução de Maria Luiza X. de A. Borges. Rio de Janeiro: Record, 1999.

JOVEM PAN. Teleton 2013 supera meta e arrecadação atinge R\$ 26.907.055. 2013. Disponível em: $<$ http://jovempan.uol.com.br/entretenimento/teleton-2013-supera-meta-e-arrecadacao-atinge-r-

26907055.html >. Acesso em 2 jan. 2015.

JAKOBI, Karin Bergit. Estado, Direito e Economia: do liberalismo clássico à "terceira via"- uma breve abordagem. In: NICZ, Alvacir Alfredo; ANDREATO, Danilo. (Coord.) Estado, Direito e Sociedade. São Paulo: Iglu, 2010.

KLIKSBERG, Bernardo. Repensando o Estado para o desenvolvimento social: superando dogmas e convencionalismos. Tradução de Joaquim Ozório Pires da Silva. São Paulo: Cortez, 1998.

LIPOVETSKY, Gilles. A sociedade pós-moralista: o crepúsculo do dever e a ética indolor dos novos tempos democráticos. Tradução de Armando Braio Ara. São Paulo: Manole, 2005.

MINISTÉRIO DO DESENVOLVIMENTO SOCIAL E COMBATE À FOME. Prestação de contas ordinárias anual - Relatório de gestão 2013. p. 21. Disponível em: <http://www.mds.gov.br/bolsafamilia/arquivos/RELAT,PC3,P93RIO,P20DE,P20GEST,PC3,P83O,P202013. pdf.pagespeed.ce.5cmS05YHYN.pdf>. Acesso em 18 jan. 2015.

PIOVESAN, Flávia. Pobreza como violação de direitos humanos. In: NOLETO, Marlova Jovchelovitch; WERTHEIN, Jorge. (Org.). Pobreza e desigualdade no Brasil: traçando caminhos para a inclusão social. Brasília: UNESCO, 2003.

PORTAL G1. Criança Esperança 2013 arrecada mais de R $\$ 10$ milhões em doações. 2013. Disponível em: $<$ http://g1.globo.com/rio-de-janeiro/noticia/2013/08/crianca-esperanca-2013-arrecada-mais-de-r10-milhoesem-doacoes.html>. Acesso em 2 jan. 2015.

Criança Esperança arrecada mais de R\$ 15 milhões em 2014. 2014. Disponível em: <http://g1.globo.com/jornal-nacional/noticia/2014/09/criancaesperanca-arrecada-mais-de-r-15-milhoes-em2014.html>. Acesso em 2 jan. 2015.

RAWLS, John. Uma teoria da Justiça. Tradução de Almiro Pisetta e Lenita M. R. Esteves. São Paulo: Martins Fontes, 2000.

RORTY, Richard. Contingência, ironia e solidariedade. Tradução de Vera Ribeiro. São Paulo: Martins Fontes, 2007

SBT. Teleton 2014 supera meta e arrecada mais de $\mathrm{R} \$ 30$ milhões. 2014. Disponível em: <http://www.sbt.com.br/teleton/fiquepordentro/15218/Teleton-2014-supera-meta-e-arrecada-mais-de-R \$30milhoes.html\#.VLgtXMY2mOM>. Acesso em 2 jan. 2015.

SEN, Amartya. A ideia de justiça. Tradução de Denise Bottmann e Ricardo Doninelli Mendes. São Paulo, Companhia das Letras, 2011. 

Letras, 2000a.

Desenvolvimento como liberdade. Tradução de Laura Teixeira Motta. São Paulo: Companhia das

Desigualdade reexaminada. Tradução de Ricardo Doninelli Mendes. Rio de Janeiro: Record, 2001.

Social exclusion: concept, applications and scrutiny. Office of Environment and Social Development Asian Development Bank, June 2000b. EBOOK.

SEN, Amartya. KLIKSBERG, Bernardo. As pessoas em primeiro lugar: a ética do desenvolvimento e os problemas do mundo globalizado. Tradução de Bernardo Ajzemberg e Carlos Eduardo Lins da Silva. São Paulo: Companhia das Letras, 2010.

SENNET, Richard. Respeito: a formação do caráter em um mundo desigual. Tradução de Ryta Vinagre. Rio de Janeiro: Record, 2004.

SIMÕES, Patrícia; SOARES, Ricardo Brito. Efeitos do Programa Bolsa Família na fecundidade das beneficiárias. In: Revista Brasileira de Economia. vol.66. n.4. Rio de Janeiro. Oct./Dec. 2012. Artigo consultado por meio do portal Scielo. Disponível em: <http://www.scielo.br/scielo.php?pid=S0034$71402012000400004 \&$ script=sci_arttext $>$. Acesso em 12 dez. 2014.

Trabalho enviado em 18 de agosto de 2015.

Aceito em 17 de setembro de 2015. 